\title{
Physiological responses of artificial moss biocrusts to dehydration-rehydration process and heat stress on the Loess Plateau, China
}

\author{
BU Chongfeng ${ }^{1,2^{*}}$, WANG Chun ${ }^{1}$, YANG Yongsheng ${ }^{3},{\text { ZHANG } \mathrm{Li}^{4} \text {, Matthew A BOWKER }}^{5}$ \\ ${ }^{1}$ Institute of Soil and Water Conservation, Northwest A\&F University, Yangling 712100, China; \\ ${ }^{2}$ Institute of Soil and Water Conservation, Chinese Academy of Sciences and Ministry of Water Resources, Yangling 712100, \\ China; \\ ${ }^{3}$ Northwest Institute of Plateau Biology, Chinese Academy of Sciences, Xining 810001, China; \\ ${ }^{4}$ Qinghai Remote Sensing Monitoring Center of Eco-Environment, Xining 810001, China; \\ ${ }^{5}$ School of Forestry, Northern Arizona University, Flagstaff 86011, USA
}

\begin{abstract}
Ex-situ cultivation of biological soil crusts (biocrusts) is a promising technology to produce materials that can induce the recovery of biocrusts in the field for the purposes of preventing soil erosion and improving hydrological function in degraded ecosystems. However, the ability of artificially cultivated biocrusts to survive under adverse field conditions, including drought and heat stresses, is still relatively unknown. Mosses can bolster biocrust resistance to the stresses (e.g., drought and heat) and the resistance may be introduced prior to field cultivation. In this study, we subjected the well-developed artificial moss biocrusts (dominant species of Didymodon vinealis (Brid.) Zand.) that we cultivated in the phytotron to a dehydration-rehydration experiment and also a heat stress experiment and measured the activities of protective enzymes (including peroxidase (POD), superoxide dismutase (SOD), and catalase (CAT)) and the contents of osmoregulatory substances (including soluble proteins and soluble sugars) and malondialdehyde (MDA, an indicator of oxidative stress) in the stem and leaf fragments of mosses. The results showed that, during the dehydration process, the activities of protective enzymes and the contents of osmoregulatory substances and MDA gradually increased with increasing duration of drought stress (over 13 days). During the rehydration process, values of these parameters decreased rapidly after $1 \mathrm{~d}$ of rehydration. The values then showed a gradual decrease for 5 days, approaching to the control levels. Under heat stress $\left(45^{\circ} \mathrm{C}\right)$, the activities of protective enzymes and the content of soluble proteins increased rapidly within $2 \mathrm{~h}$ of heat exposure and then decreased gradually with increasing duration of heat exposure. In contrast, the contents of soluble sugars and MDA always increased gradually with increasing duration of heat exposure. This study indicates that artificial moss biocrusts possess a strong drought resistance and this resistance can be enhanced after a gradual dehydration treatment. This study also indicates that artificial moss biocrusts can only resist short-term heat stress (not long-term heat stress). These findings suggest that short-term heat stress or prolonged drought stress could be used to elevate the resistance of artificial moss biocrusts to adverse conditions prior to field reintroduction.
\end{abstract}

Keywords: dehydration-rehydration; heat stress; Didymodon vinealis (Brid.) Zand.; resistance; Loess Plateau

Citation: BU Chongfeng, WANG Chun, YANG Yongsheng, ZHANG Li, Matthew A BOWKER. 2017. Physiological responses of artificial moss biocrusts to dehydration-rehydration process and heat stress on the Loess Plateau, China. Journal of Arid Land, 9(3): 419-431. doi: 10.1007/s40333-017-0057-8

*Corresponding author: BU Chongfeng (E-mail: buchongfeng@163.com)

Received 2016-08-29; revised 2016-12-12; accepted 2017-04-01

(C) Xinjiang Institute of Ecology and Geography, Chinese Academy of Sciences, Science Press and Springer-Verlag Berlin Heidelberg 2017 


\section{Introduction}

Mosses are an ancient lineage of plants lacking vascular tissue and root systems, and therefore exhibit fundamentally different water use mechanisms compared with vascular plants (Proctor et al., 2007). These poikilohydric plants are characterized by hydrating when in contact with water, and they lose water mainly through simple evaporation. Despite their reliance on the presence of water for physiological activities, some mosses can tolerate desiccation (Robinson et al., 2000) and are common in the drylands of the world, where they are members of highly functional biocrust (biological soil crust) communities. As members of biocrust communities, mosses contribute to the key ecosystem functions in the drylands, such as fixing dunes (West, 1990), increasing soil fertility (Yang et al., 2015), improving soil structure (Gao et al., 2014), enhancing resistance to water erosion (Xiao et al., 2011) and also to wind erosion (Zhang et al., 2006), buffering microbial communities from climate change (Delgado-Baquerizo et al., 2016), and influencing the germination and survival of seeds (Peter et al., 2016). These functions, however, are easily lost because moss biocrusts (biological soil crusts) are highly susceptible to ground surface disturbances. The natural recovery of moss biocrusts from disturbance is especially long and is highly variable from place to place (Weber et al., 2016). Therefore, the rapid artificial cultivation of moss biocrusts is of great practical significance to potentially accelerate the recovery of moss biocrusts in disturbed ecosystems (Chiquoine et al., 2016). Only very recently, several artificial cultivation methods of moss biocrusts were developed, confirming that the technology of rapid artificial cultivation of moss biocrusts is practical (Chen, 2009; Bu et al., 2014, 2015; Doherty et al., 2015; Yang et al., 2015; Antoninka et al., 2016). During artificial cultivation, growth-favoring environmental conditions (such as near-optimal and relatively invariant soil moisture, air humidity, temperature, and light) were often artificially created to rapidly form the moss biocrusts. Thus, these methods may not be ideal to prepare moss biocrusts for later application in the field, where environmental factors are variable and sometimes are harsh. Therefore, developing the artificial cultivation methods towards wider and larger-scale field applications is widely anticipated.

Drought and heat are two main stress factors limiting the survival of moss biocrusts in the field. Mosses possess special mechanisms of drought resistance, such as rapid response to limited water supply (Zou, 2015). They can maintain the carbohydrates during long-term dehydration and retain the ability to restore photosynthesis upon rehydration (Robinson et al., 2000). One major outcome of dehydration is oxidative damage. Generally speaking, gradual drying allows mosses to desiccate unharmed, whereas rapid drought events may lead to severe damages to mosses (Stark et al., 2013). Despite that many of the habitats of moss biocrusts do endure higher temperatures $\left(38^{\circ} \mathrm{C}-40^{\circ} \mathrm{C}\right)$, mosses are generally adapted to photosynthetic optima at lower temperatures $\left(10^{\circ} \mathrm{C}-28^{\circ} \mathrm{C}\right.$; Lange, 2003). Heat stress can cause protein denaturation and structural damage to biological membranes in plants in general, subsequently causing physiological and biochemical metabolic disorders and ultimately leading to the necrosis of tissues or even whole plants $(\mathrm{Xu}$ and Zhang, 2009). Heat stress can reduce the ability of mosses to regenerate (McLetchie and Stark, 2006; Stark and McLetchie, 2006).

In this study, we subjected the artificial moss biocrusts to the alternating drying and wetting conditions (dehydration-rehydration process) simulated by artificial control of soil water content. In parallel, we subjected the artificial moss biocrusts to a high-temperature environment using an intelligent incubator. We tested the hypothesis that gradual dehydration (drying condition) would induce marks of oxidative stress (expressed by malondialdehyde (MDA)) and also marks of resistance to oxidative stress in the forms of protective enzymes (including peroxidase (POD), superoxide dismutase (SOD), and catalase (CAT)) and osmoregulatory substances (including soluble proteins and sugars). After this "hardening" process, we expected to observe a "dehardening" under sustained rehydration (wetting) conditions. We also tested the hypothesis that the stress response of hydrated mosses to high temperatures may trigger a similar set of responses. This hypothesis is based on two previous observations. First, synthesis of protective enzymes has also been observed in vascular plants in response to heat stress (Almeselmani et al., 
2006). Second, heat may decrease the membrane integrity in mosses and would thus induce a need for osmoregulatory substances (Xu et al., 2009). Therefore, it may be possible to use the physiological responses of artificial moss biocrusts to non-lethal dehydration-rehydration and heat exposure to induce the resistance mechanisms to these stresses (i.e., drought and heat) in drylands. It is our hope that the findings would further improve the engineering application of artificial moss biocrusts in degraded ecosystems and also in harsh environments.

\section{Materials and methods}

\subsection{Experimental design}

Moss biocrusts were collected from a semi-sunny slope in the Majiagou Watershed $\left(36^{\circ} 47^{\prime} 58^{\prime \prime} \mathrm{N}\right.$, $109^{\circ} 15^{\prime} 32^{\prime \prime}$ ) of Ansai County, Shaanxi Province, China. This region is located in the hilly region of the Loess Plateau and characterized by a semi-arid continental and monsoonal climate. The annual average temperature is $8.8^{\circ} \mathrm{C}$ and the average annual precipitation is $520 \mathrm{~mm}$. The soil characteristics are listed in Table 1.

Table 1 Soil physic-chemical properties in the study area

\begin{tabular}{cccccccc}
\hline $\begin{array}{c}\text { Soil organic matter } \\
(\mathrm{g} / \mathrm{kg})\end{array}$ & $\begin{array}{c}\text { Total N } \\
(\mathrm{g} / \mathrm{kg})\end{array}$ & $\begin{array}{c}\text { Total P } \\
(\mathrm{g} / \mathrm{kg})\end{array}$ & $\begin{array}{c}\text { Available N } \\
(\mathrm{g} / \mathrm{kg})\end{array}$ & $\begin{array}{c}\text { Available P } \\
(\mathrm{g} / \mathrm{kg})\end{array}$ & $\begin{array}{c}\text { Silt content } \\
(\%)\end{array}$ & $\begin{array}{c}\text { Clay content } \\
(\%)\end{array}$ & $\begin{array}{c}\text { Sand content } \\
(\%)\end{array}$ \\
\hline 9.00 & 0.65 & 0.55 & 1.11 & 24.10 & 67.80 & 5.53 & 26.67 \\
\hline
\end{tabular}

Note: N, nitrogen; $\mathrm{P}$, phosphorus.

The dominant species of moss biocrusts in the field was identified as Didymodon vinealis (Brid.) Zand., and the accompanying species were Barbula indica (Hook.) Spreng., Trichostomum crispulum Bruch, Didymodon ditrichoides (Broth.), and Bryum caespiticium Hedw. with a low coverage. $D$. vinealis was specifically targeted in our collections. In the field sampling, moss biocrusts with thickness of $10 \mathrm{~mm}$ were collected and impurities that were discernible with the naked eye (e.g., litter, soil aggregates, and coarse rock fragments) were removed. Then, the sampled moss biocrusts were shoveled into clean plastic bags, brought back to the laboratory and allowed to dry in the shade under natural conditions. The collected moss biocrusts were crushed and spread over the surface of the cultivation boxes (length of $242 \mathrm{~mm}$, width of $168 \mathrm{~mm}$, and height of $50 \mathrm{~mm}$ each) containing loess soil (depth of $40 \mathrm{~mm}$ ) obtained from the sampling sites, and the depth of crushed moss biocrusts was $5 \mathrm{~mm}$. There were a total of 51 cultivation boxes in this study. Cultivation was performed for a period of $65 \mathrm{~d}$ in a phytotron (AGC-D003N, China; Fig. 1) at the Institute of Soil and Water Conservation, Chinese Academy of Sciences and Ministry of Water Resources, China. We set the parameters of the phytotron based on our previous results $\left(\mathrm{Bu}\right.$ et al., 2015), i.e., light intensity $=1000$ lux, humidity $=60 \%$, and $\mathrm{CO}_{2}$ concentration $=400 \mu \mathrm{mol} / \mathrm{mol}$. During the cultivation period, soil water content in the topsoil layer (1-cm depth) was maintained at $25 \%-30 \%$ by regular watering through micro spraying with 50 $\mathrm{mL} / \mathrm{min}$ flow, and $45 \mathrm{~mL}$ of Hoagland nutrient solution was sprayed every $20 \mathrm{~d}$ to each cultivation box. The dominant species of the cultivated mosses was confirmed to be $D$. vinealis, which is the same as the dominant species identified in the field and is the target species in our experiments.

Among 51 cultivation boxes, 44 boxes had the healthiest moss plants that grew uniformly after the cultivation. Thus, they were selected for the later experiments and treated as one large population. Of the 44 cultivation boxes, 24 boxes were used to conduct the dehydration-rehydration experiment with 6 time points, and 20 boxes were used to conduct the heat stress experiment with 5 time points. For both experiments, 4 cultivation boxes were sampled at each time point, with 2 representing controls and 2 representing treatments. During a sampling event, 3 equal-area samples were collected from the 2 boxes representing a given treatment.

\subsection{Experimental process}

\subsubsection{Dehydration-rehydration process}

For the dehydration-rehydration experiment, 12 cultivation boxes (treated samples) were evenly 


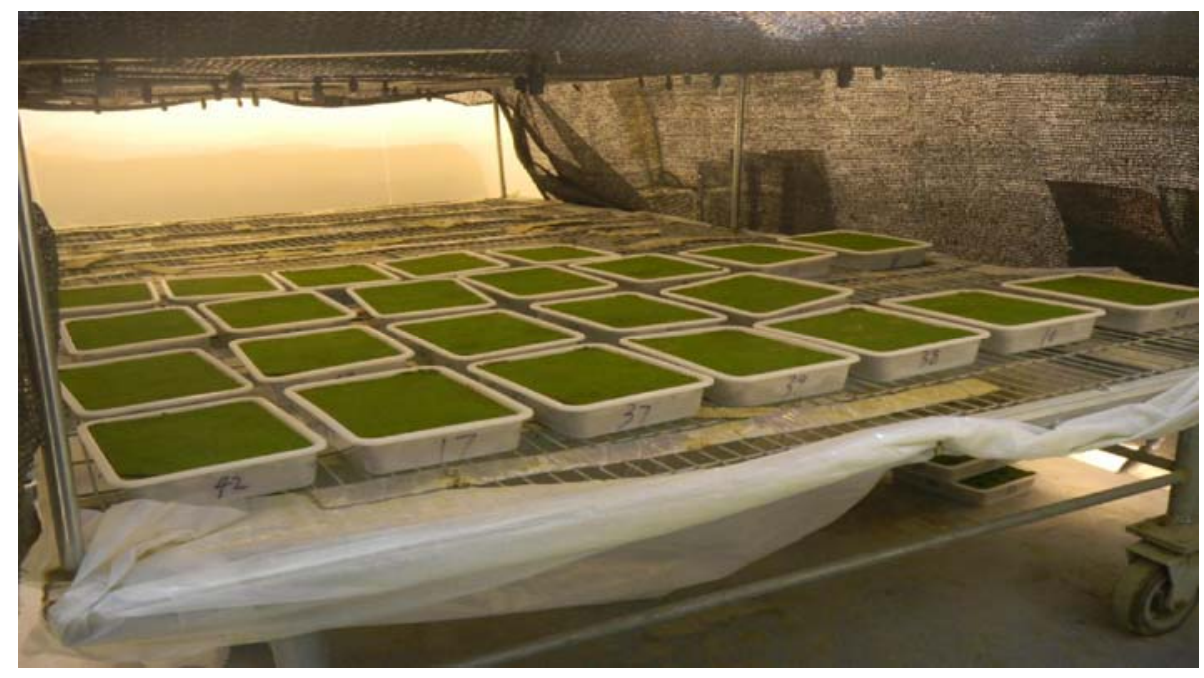

Fig. 1 Layout of the moss biocrust cultivation in the phytotron

placed on the cultivation table in the phytotron (light intensity $=1000$ lux, air humidity $=60 \%$, and photoperiod $=12 \mathrm{~h}$ ) and were naturally dried for $13 \mathrm{~d}$ during the dehydration process. In contrast, the other 12 cultivation boxes were normally watered and were used as the control samples (soil water content in the topsoil layer (1-cm depth) maintaining at $25 \%-30 \%)$. Stem and leaf fragments of moss plants were collected on the $1^{\text {st }}, 7^{\text {th }}$, and $13^{\text {th }}$ days during the dehydration (drought) process. For each set of samples, 3 equal-area samples were collected from 2 cultivation boxes subjected to dehydration-rehydration treatment, and 3 equal-area samples were also collected from 2 cultivation boxes subjected to control treatment. The dehydration process was followed by a rehydration process.

The rehydration process involved uniformly spraying $70 \mathrm{~mL}$ of distilled water over every treatment for every morning and every evening. Stem and leaf fragments from the moss plants were collected on the $1^{\text {st }}, 3^{\text {rd }}$, and $5^{\text {th }}$ days after rehydration, using the same procedure as described above. All the collected stem and leaf fragments were wrapped in aluminum foil and immediately frozen in liquid nitrogen for $3 \mathrm{~min}$. The frozen samples were then stored at $-20^{\circ} \mathrm{C}$ in a freezer and were used to analyze the physiological parameters.

Soil water content in the topsoil layer (1-cm depth) was gravimetrically determined by oven-drying method and the data are presented in Figure 2. Soil water content of topsoil layer (1-cm depth) in the control samples was relatively stable, generally maintaining between $30 \%$ and $32 \%$ throughout the experimental period. During the dehydration process, soil water content of topsoil layer (1-cm depth) in the treated samples decreased sharply, with the lowest value (5\%) observed on the $13^{\text {th }}$ day (the end of the dehydration process). In contrast, soil water content increased dramatically during the rehydration process and reached the control level on the $5^{\text {th }}$ day after rehydration.

\subsubsection{Heat stress process}

For the heat stress experiment, the 20 cultivation boxes were placed in an intelligent incubator (ZPW-280B, China) with light intensity of 1000 lux and air humidity of $60 \%$. For the 10 treated cultivation boxes, the temperature was set to $45^{\circ} \mathrm{C}$; while for the 10 control cultivation boxes, the temperature was set to $20^{\circ} \mathrm{C}$. Stem and leaf samples were collected after the cultivation boxes had been in the incubator for 1, 2, 4, 6 and $8 \mathrm{~h}$, using the same sampling method and storage procedure with the dehydration-rehydration experiment. These samples were then used to analyze the physiological parameters.

\subsection{Measurements of physiological parameters}

For all stem and leaf samples, peroxidase (POD) activity was measured by the guaiacol assay (Scebba et al., 1999). Superoxide dismutase (SOD) activity was measured using the nitro blue 


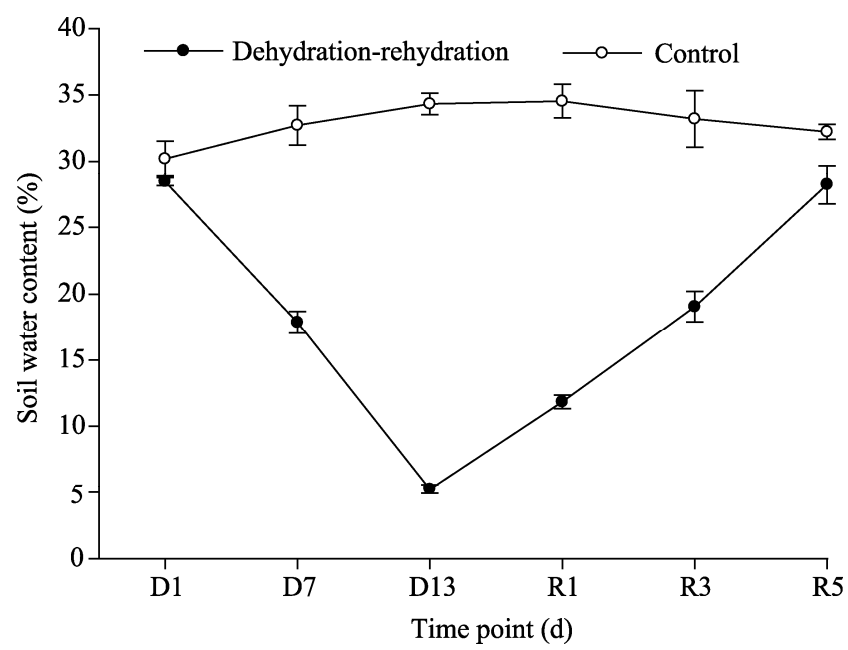

Fig. 2 Soil water contents of topsoil layer (1-cm depth) in the control and treated samples during the dehydration-rehydration experiment. D1, D7, and D13 represent the $1^{\text {st }}, 7^{\text {th }}$, and $13^{\text {th }}$ days during the dehydration process; R1, R3, and R5 represent the $1^{\text {st }}, 3^{\text {rd }}$, and $5^{\text {th }}$ days after rehydration. Bars mean standard errors.

tetrazolium reduction method (Scebba et al., 1999). Catalase (CAT) activity was measured using the hydrogen peroxide reduction method (Scebba et al., 1999). Malondialdehyde (MDA) content was measured by the thiobarbituric acid assay (Dionisio-Sese and Tobita, 1998). And, contents of soluble sugars and proteins were measured using the anthrone colorimetry and Coomassie blue methods, respectively (He et al., 2008). In all cases, measurements were conducted using a UV Spectrophotometer (UV2300, China).

\subsection{Statistical analysis}

For the dehydration-rehydration experiment, all indicators of oxidative stress, osmoprotectant synthesis, and antioxidant synthesis were analyzed using two-way ANOVA in JMP Pro 12 (2015 SAS Inst., USA), with the factors of (1) dehydration-rehydration, (2) time point, and (3) the interaction of dehydration-rehydration and time point. For the heat stress experiment, the analysis method was the same as that of the dehydration-rehydration experiment, with the factors of (1) heating, (2) time point, and (3) the interaction of heating and time point. Prior to ANOVA analysis, the response variables were tested for normality using the Shapiro-Wilk test, and homogeneity of variance was tested using the Levene's test. It should be noted that although some minor departures from normality occurred, we corrected them to have unequal variances. Thus, all analyses were based on untransformed data.

\section{Results}

\subsection{Effect of dehydration-rehydration on artificial moss biocrusts}

\subsubsection{Effect of dehydration-rehydration on protective enzymes}

The activities of all protective enzymes (including POD, CAT, and SOD) exhibited a similar response to the dehydration-rehydration treatment (Fig. 3). For the three factors (i.e., dehydration-rehydration, time point, and the interaction of dehydration-rehydration and time point), dehydration-rehydration was the most influential factor in all cases (Table 2). During the whole dehydration-rehydration experiment, the activities of SOD (Fig. 3a), POD (Fig. 3b), and CAT (Fig. 3c) in the control samples were relatively stable. However, the activities of SOD, POD, and CAT in the treated samples increased rapidly and reached a peak on the $13^{\text {th }}$ day of the dehydration process (Fig. 3). The second most influential factor on the activities of protective enzymes was the interaction of dehydration-rehydration and time point (Table 2), reflecting a strong decline of enzyme activities in the treated samples after rehydration and a return to values being similar to those observed in the control samples. Furthermore, a main effect of time point 
on the activities of POD and CAT was detected (Table 2), and the effect appeared to be driven entirely by the strong temporal dynamics of protective enzymes in the treated samples.
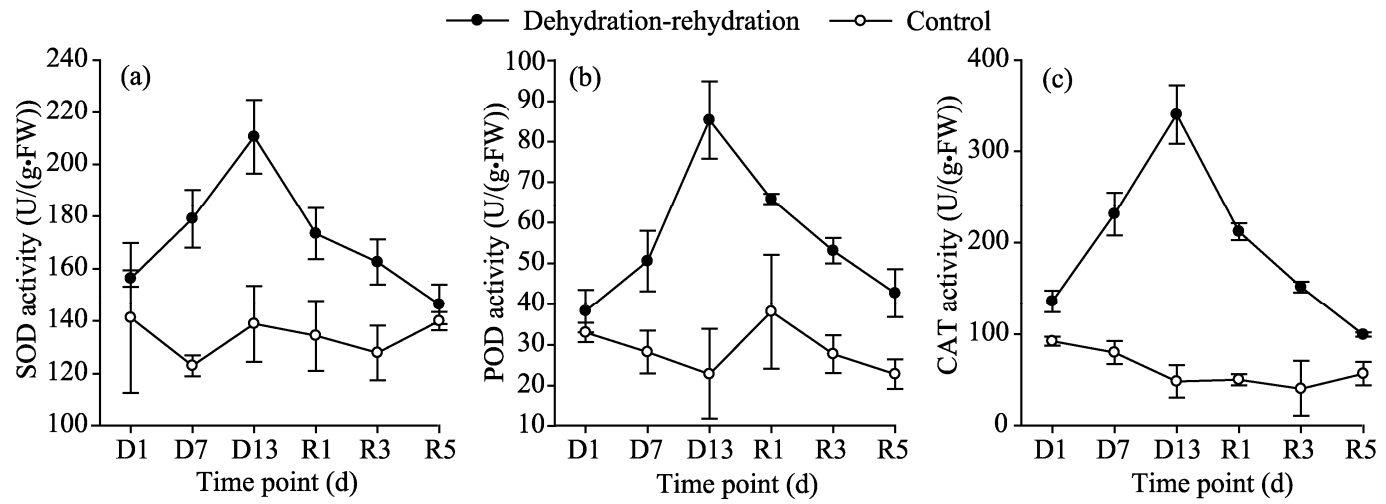

Fig. 3 Activities of protective enzymes in the control and treated artificial mosses during the dehydration-rehydration experiment. (a), SOD (superoxide dismutase); (b), POD (peroxidase); (C), CAT (catalase). Bars mean standard errors.

Table 2 ANOVA results for the physiological parameters of the artificial mosses during the dehydration-rehydration experiment

\begin{tabular}{|c|c|c|c|c|c|c|}
\hline \multirow{2}{*}{ Physiological parameter } & \multicolumn{2}{|c|}{ Dehydration-rehydration (D-R) } & \multicolumn{2}{|c|}{ Time point } & \multicolumn{2}{|c|}{$\mathrm{D}-\mathrm{R} \times$ time point } \\
\hline & $F$ & $P$ & $F$ & $P$ & $F$ & $P$ \\
\hline SOD & 25.9 & $<0.0001$ & 1.6 & 0.1800 & 1.9 & 0.1400 \\
\hline POD & 44.0 & $<0.0001$ & 3.0 & 0.0300 & 3.6 & 0.0200 \\
\hline CAT & 185.7 & $<0.0001$ & 12.3 & $<0.0001$ & 15.0 & $<0.0001$ \\
\hline Soluble proteins & 53.7 & $<0.0001$ & 4.2 & 0.0070 & 5.9 & $<0.0001$ \\
\hline Soluble sugars & 124.2 & $<0.0001$ & 7.5 & 0.0030 & 11.9 & $<0.0001$ \\
\hline MDA & 101.4 & $<0.0001$ & 6.7 & 0.0005 & 9.4 & $<0.0001$ \\
\hline
\end{tabular}

Note: SOD, superoxide dismutase; POD, peroxidase; CAT, catalase; MDA, malondialdehyde.

\subsubsection{Effect of dehydration-rehydration on osmoregulatory substances and MDA}

The responses of osmoregulatory substances (including soluble proteins and soluble sugars) to dehydration-rehydration were similar to those of protective enzymes (Table 2; Fig. 4). In the control samples, with sufficient soil water content in the topsoil layer (1-cm depth), the contents of soluble proteins, soluble sugars and MDA varied and maintained at relatively low levels (Fig. 4). In the treated samples, however, the contents of all these three parameters increased rapidly and reached their maximal values on the $13^{\text {th }}$ day of the dehydration process. During the rehydration process, the soluble protein content declined over time, approaching to the control level on the $5^{\text {th }}$ day after rehydration (Fig. 4a). The soluble sugar content showed an irregular variation during the rehydration process, i.e., declining sharply on the $1^{\text {st }}$ day after rehydration, increasing slightly on the $3^{\text {rd }}$ day, and again declining rapidly on the $13^{\text {th }}$ day (Fig. $4 \mathrm{~b}$ ). Furthermore, the content of MDA declined dramatically during the rehydration process and approached to the control level at the end of the rehydration process (Fig. 4c).

\subsection{Effect of heat stress on artificial moss biocrusts}

\subsubsection{Effect of heat stress on protective enzymes}

The optimal temperature for the growth of moss biocrusts is generally between $15^{\circ} \mathrm{C}$ and $25^{\circ} \mathrm{C}$. As shown in Figure 5, the activities of SOD, POD, and CAT in the control samples varied and maintained at relatively low levels. Treated samples exposed to heat stress of $45^{\circ} \mathrm{C}$ exhibited elevated activity levels of all protective enzymes at almost all time points. For the three factors (including heating, time point, and the interaction of heating and time point), heating was the factor that exerted the strongest effect on the activities of protective enzymes (SOD, POD, and 
CAT) in all cases (Table 3). The interaction of heating and time point also influenced the activities of protective enzymes, although to a lesser degree. For example, the activities of protective enzymes reached the peak (26\%-36\% higher than controls) after about $2 \mathrm{~h}$ of heat exposure and then slightly declined afterward (Table 3; Fig. 5). It should be noted that the effect of time point on the activities of protective enzymes was not detectable (Table 3 ).
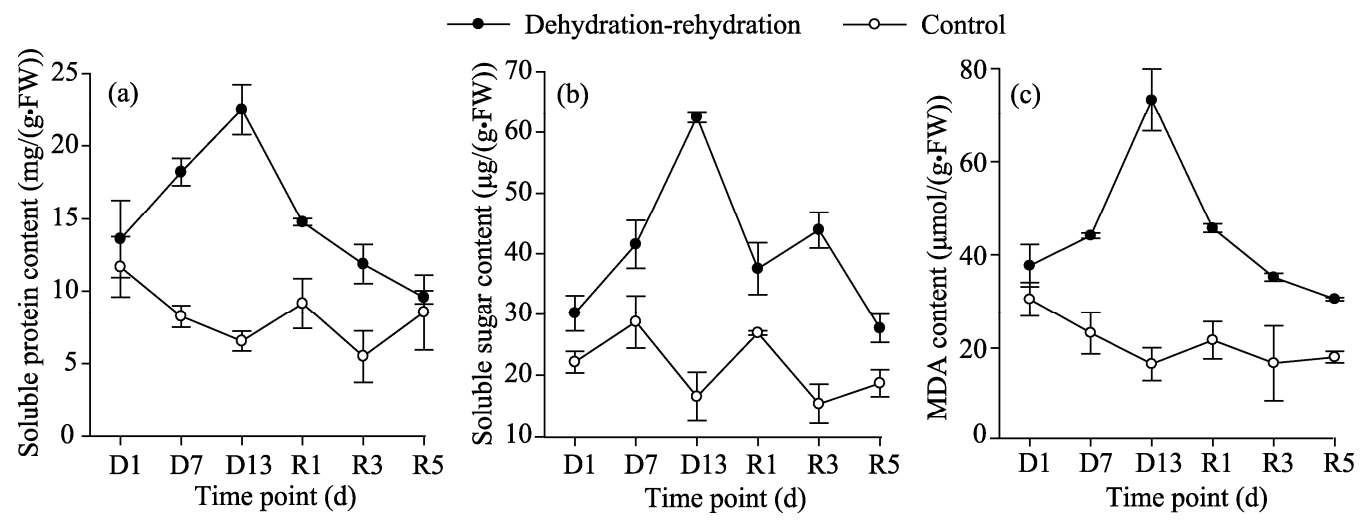

Fig. 4 Contents of osmoregulatory substances (a,b) and MDA (c) in the control and treated artificial mosses during the dehydration-rehydration experiment. MDA, malondialdehyde. Bars mean standard errors.
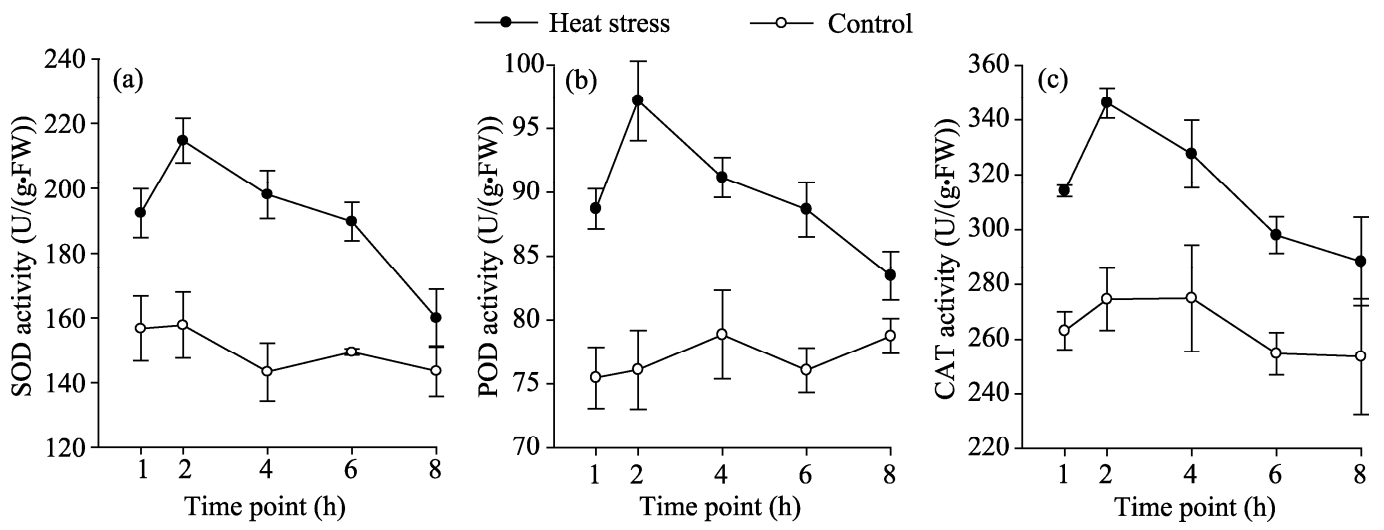

Fig. 5 Activities of protective enzymes in the control and treated artificial mosses during the heat stress experiment. (a), SOD; (b), POD; (C), CAT. Bars mean standard errors.

Table 3 ANOVA results for the physiological parameters of the artificial mosses during the heat stress experiment

\begin{tabular}{|c|c|c|c|c|c|c|}
\hline \multirow{2}{*}{ Physiological parameter } & \multicolumn{2}{|c|}{ Heating } & \multicolumn{2}{|c|}{ Time point } & \multicolumn{2}{|c|}{ Heating $\times$ time point } \\
\hline & $F$ & $P$ & $F$ & $P$ & $F$ & $P$ \\
\hline SOD & 10.3 & 0.005 & 0.8 & 0.55 & 2.2 & 0.11 \\
\hline POD & 15.9 & 0.001 & 0.5 & 0.75 & 3.0 & 0.04 \\
\hline CAT & 8.5 & 0.008 & 0.7 & 0.60 & 0.6 & 0.65 \\
\hline Soluble proteins & 8.7 & 0.008 & 0.2 & 0.95 & 0.6 & 0.69 \\
\hline Soluble sugars & 5.0 & 0.040 & 0.5 & 0.73 & 1.9 & 0.16 \\
\hline MDA & 5.6 & 0.030 & 0.9 & 0.47 & 0.7 & 0.63 \\
\hline
\end{tabular}

\subsubsection{Effect of heat stress on osmoregulatory substances and MDA}

The responses of soluble proteins to heat stress were very similar to those of protective enzymes (Table 3; Fig. 6a). Generally speaking, the soluble protein content was higher in the treated samples than in the control samples. The heating effect was rapidly induced after the initiation of heat exposure, reaching the maximum after about $2 \mathrm{~h}$, and it then declined gradually (Fig. 6a). 
The contents of soluble proteins and MDA appeared to have gradually increased over the whole heat stress experiment $(\sim 17 \%$ greater than controls in the case of soluble proteins, and $\sim 33 \%$ greater than controls in the case of MDA; Figs. $6 \mathrm{~b}$ and c). Of the three factors (including heating, time point, and the interaction of heating and time point), heating was the only factor influencing the contents of osmoregulatory substances and MDA (Table 3).
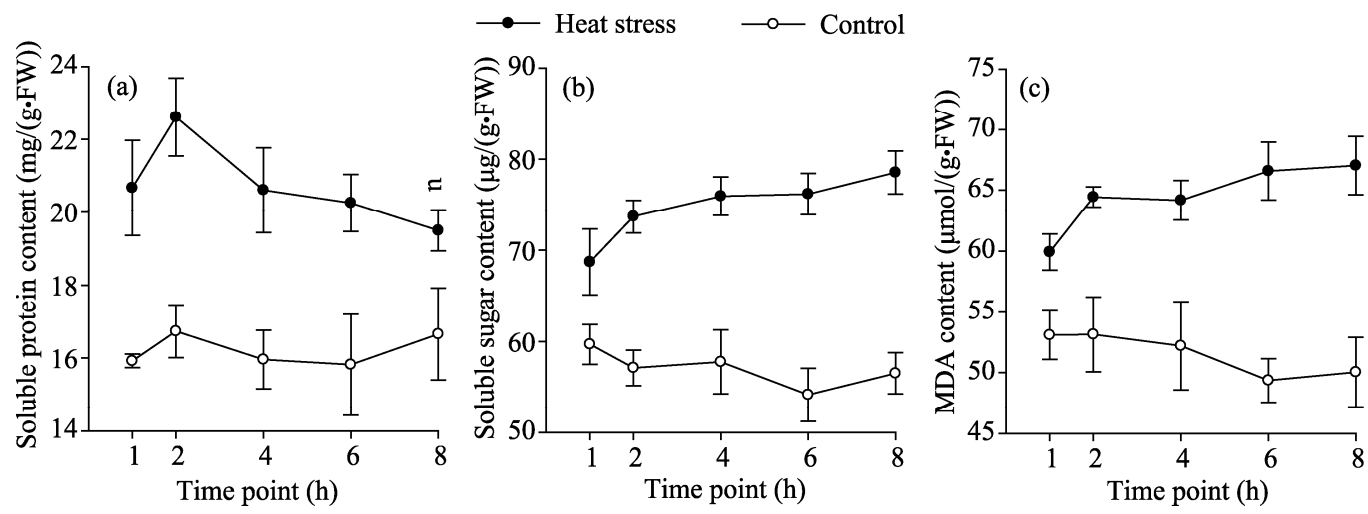

Fig. 6 Contents of osmoregulatory substances (a, b) and MDA (c) in the control and treated artificial mosses during the heat stress experiment. Bars mean standard errors.

\section{Discussion}

\subsection{Physiological responses of artificial moss biocrusts to dehydration-rehydration process}

The results of this study lend supports to our hypotheses that dehydration would induce the production of protective enzymes and osmoregulatory substances, an expression of "hardening". Some of these responses can be mechanistically understood as the result of the generation of reactive oxygen species (ROS). Generally, ROS in plants can be induced to generate under adverse conditions, such as drought and heat stresses (Scandalios, 1997). ROS play important physiological roles in plant development and may also control some biological processes (Novo-Uzal et al., 2013). When ROS accumulate beyond a certain range, they will cause membrane lipid peroxidation and cell death, thereby injuring the plants (Imlay, 2003; Kärkönen and Kuchitsu, 2015). The production of protective enzymes (such as SOD, POD, and CAT) is one strategy that plants (including mosses) defend themselves against free radical injury during dehydration (Seel et al., 1991; Oliver and Bewley, 2010). These enzymes can clear the excess ROS in plants and maintain the metabolism of ROS ions in a dynamic balance (Mayaba and Beckett, 2003; Shi and Liu, 2010) that prevents free radical injury. For mosses, different species appear to vary in their ability to induce the production of protective enzymes in response to dehydration (Dhindsa and Matowe, 1981; Seel et al., 1992). In our dehydration-rehydration experiment, the activities of SOD, POD, and CAT in the artificial D. vinealis increased rapidly from the start to the end of the dehydration process, indicating an inducible defense capability against ROS (Chen et al., 2013). After rehydration (rewatering), however, the activities of all protective enzymes decreased substantially, suggesting that the dynamic balance that disrupted by the increased ROS had been restored in plants. Our result that the activities of protective enzymes in the artificial $D$. vinealis increased with time under drought stress is different from those in Taxiphyllum taxirameum (Mitt.) Fleisch. and Brachythecium moriense Besch., in which the activities of protective enzymes decreased with time under drought stress (Cao et al., 2014). The discrepancy between these results indicates that different moss species may exhibit fundamentally different responses to dehydration and to excess ROS. Thus, additional data on a larger number of taxa sourced from a wide range of habitats including drylands and deserts are needed to elevate our understanding.

In our study, the dehydration-rehydration experiment did not cause irreversible oxidative damage to the artificial mosses, as indicated by the increase of MDA content during the 
dehydration process and decrease of MDA content during the rehydration process. MDA, a membrane lipid peroxide in plant cells, can lead to cross-linking mediated deactivation of intracellular enzymes and can enhance cell membrane permeability. The generation and accumulation of ROS in plants under adverse conditions is a key event that leads to the increase of MDA content. The MDA level can reflect the intensity of cell membrane lipid peroxidation in plants. Our results showed that during the dehydration process, the MDA content increased slowly during the first 7 days and then increased rapidly towards the end of the dehydration process. The initial slow increase and subsequent rapid increase in MDA content may suggest that although protective enzymes were effective in constraining the oxidative damage, the damage was eventually incurred in the membrane system. Nonetheless, the substantial resilience of mosses to this damage was evident. After rehydration (rewatering), the injured cells began to repair (Ortuño et al., 2005), so that the damaged cell membrane recovered and the plant metabolism gradually returned to a norm. Probably, because the excess ROS induced by the drought were cleared by the protective enzymes, the MDA content decreased after rehydration. Although the symptoms of plant damage were relieved to a certain degree, it never recovered to the undamaged state (control level) over the course of the experiment.

Another strategy of mosses to prevent oxidative damage under drought stress (dehydration) is losing water at a low rate. Under drought stress, soil water content gradually decreases and water potential is gradually lowered. Thus, mosses must lower the water potential in their own cells to absorb water and maintain the normal physiological activities. The accumulation of osmoregulatory substances within plant cells is the key process in improving their osmoregulatory ability (Shackel et al., 1982). Soluble proteins and sugars are the major constituents of osmoregulatory substances. In the present study, both the soluble protein and sugar contents gradually increased along with increasing duration of drought stress, being consistent with the role of osmoregulation. Under drought stress, the soluble protein content may increase for two reasons. First, the decomposition of macromolecular carbohydrates and proteins is enhanced while the synthesis is inhibited under adverse conditions (Guo et al., 2014). Second, plants can induce the synthesis of new water stress proteins or transform some insoluble proteins into soluble proteins in cells to reduce the damage caused by dehydration (Kang et al., 2005). Under drought stress, the soluble sugar content increases because plants can accumulate a considerable amount of highly soluble low-molecular-weight organic compounds, which are structurally stable and difficult to metabolize (Iba, 2002). These soluble compounds include sucrose, trehalose, mannitol, and other sugar alcohols (Toldi et al., 2009). The soluble sugars may play important roles in the desiccation tolerance of some mosses, including Syntrichia caninervis, a model taxon for the study of desiccation tolerance (Wu et al., 2012). During the dehydration process, in addition to contributing to osmoregulation, soluble sugars may also contribute to the vitrification of the cell membrane, protecting it from being damaged (Wu et al., 2012). After rehydration (rewatering), the external water potential increases, making it necessary for cells to increase their internal water potential and thus to maintain the normal cell turgor. Consequently, the contents of soluble proteins and sugars decrease.

\subsection{Physiological responses of artificial moss biocrusts to heat stress}

Temperature is another important factor influencing plant growth and development. Direct heat damage to plants includes protein denaturation and aggregation and increased membrane fluidity (McClung and Davis, 2010). And, indirect heat damage to plants includes enzyme inactivation in mitochondria and chloroplasts, inhibition of protein synthesis, promotion of protein degradation, and destruction of membrane integrity (Howarth, 2005). Heat stress is often associated with water loss, thus we hypothesized that some of the responses of artificial moss biocrusts to drought stress would also be observable under heat stress. In the present study, the activities of protective enzymes in the treated artificial mosses initially increased rapidly in the first $2 \mathrm{~h}$ of heat exposure $\left(45^{\circ} \mathrm{C}\right)$, and then decreased as the heat exposure at $45^{\circ} \mathrm{C}$ continued. This trend is consistent with the results observed in Hypnum fertile Sendtn. (Shen et al., 2011) and Haplocladium microphyllum (Hedw.) Broth. (Chen, 2012). Simultaneously, the MDA content increased rapidly 
with the extent lesser than the activities of protective enzymes in the first $2 \mathrm{~h}$ of heat exposure. But, after $2 \mathrm{~h}$ of heat exposure, it increased only gradually and never reached the values observed in the dehydration process. These observations may suggest that the short-term heat stress was only as effective for inducing the protective enzymes and it incurred much less injuries to plants than dehydration did, meaning that the artificial moss biocrusts could resistant to a certain degree of heat stress. Thereafter, the increased duration of heat stress may exacerbate cell membrane lipid peroxidation (Anderson, 2002), causing the structural damage to protective enzymes (Howarth, 2005).

Dehydration of plant cells due to heat stress is a major cause of heat-induced injury (Liu and Zhang, 1994). The lipid bilayer of cell membrane exists in a liquid crystal phase. Excessively high temperatures can lead to protein denaturation and aggregation, thereby increasing cell membrane permeability (Ashraf and Harris, 2005). In the present study, the contents of soluble sugars and proteins in cells of artificial mosses markedly increased under heat stress at $45^{\circ} \mathrm{C}$, indicating that the artificial mosses can reduce plant damage by increasing the contents of soluble sugars and proteins under heat stress. However, the contents of soluble sugars and proteins showed different variation trends in responses to heat stress. The soluble proteins possess high hydrophilicity, and the increased content of soluble proteins in cells can improve the water retention capacity (Xia et al., 2010). Under heat stress, the synthesis of most common proteins and messenger RNAs (ribonucleic acids) is inhibited. Plants will then induce the production of stress proteins called "heat shock proteins" and will mainly produce small heat shock proteins (sHSPs). These sHSPs have multiple functions and these functions include: acting as molecular chaperones to reduce the abnormal accumulation of proteins, binding incorrect peptides to degrade them, and inducing proper protein folding. Furthermore, these sHSPs can also degrade and clear the abnormal proteins of cells (Feder and Hofmann, 1999), thereby maintaining the normal physiological activities of cells. In our study, within the first $2 \mathrm{~h}$ of heat stress, the soluble protein content and the activities of protective enzymes showed increasing trends with increasing duration of heat exposure. These results indicate that soluble proteins play an important role in improving the heat resistance of artificial mosses at the early stages of heat stress. The soluble protein content in the artificial mosses gradually decreased after $2 \mathrm{~h}$ of heat stress. It is almost certain that the heat stress at $45^{\circ} \mathrm{C}$ greatly exceeds the optimal growth temperature of moss biocrusts. In fact, it was reported that most mosses experience mortality under 30-60-min exposure to similar $\left(45^{\circ} \mathrm{C}\right)$ or slightly higher temperatures (Stark et al., 2009). In our study, with increasing duration of heat exposure, the sHSPs were also adversely affected, thereby suppressing intracellular protein synthesis and resulting in increased accumulation of degenerated and aggregated abnormal proteins. Ultimately, the membrane integrity was lost (Howarth, 2005) and various physiological activities were adversely affected. The soluble sugar content increased rapidly during the early stages of drought stress, and subsequently the rate of increase slowed down. This pattern may have occurred because exposure to a high temperature (e.g., $45^{\circ} \mathrm{C}$ ) is associated in nature not only with high-temperature stress but also with drought stress. In our study, at the early stages of heat stress, an increase in stress proteins contributed to a degree of heat resistance in the artificial moss biocrusts, and the increased protective enzyme activities could have preserved the normal physiological activities in cells. However, the mosses, as typical of poikilohydric plants, can be dehydrated and dried under a long-time exposure to high temperature. We might hypothesize that heat stress could trigger additional mechanisms of drought resistance for mosses within a short-time period, steadily accumulating large quantities of highly soluble sugars (Zhang et al., 2004). With increasing duration of heat stress, the physiological activities of plant cells were eventually affected, thus slowing down the rate of increase.

\subsection{Recommendations for field application of artificial moss biocrusts}

Moss biocrusts can be grown artificially for the intended use of ecological rehabilitation (Chen, 2009; Bu et al., 2014, 2015; Doherty et al., 2015; Antoninka et al., 2016). Although this technology needs refinement and up-scaling (Antoninka et al., 2016), a major remaining technical 
hurdle to overcome in the development of artificial moss biocrusts as a rehabilitation material is the successful survival of artificial moss biocrusts under harsh environments. One approach to this problem would be to harden the moss biocrusts prior to field reintroduction, by inducing the natural resistance mechanisms of mosses through stresses brought by heat and drought. As an example of hardening, vascular plants can acquire heat resistance through non-lethal heat training in a process termed heat acclimation (Gulen and Eris, 2003). We hypothesize that hardened mosses with higher activities of protective enzymes and higher contents of soluble sugars and proteins may be better to survive in naturally-harsh environments. In the present study, all physiological responses of artificial moss biocrusts were inducible by brief non-lethal exposure to heat or drought. Future experiments are needed to determine whether such hardening activities can enhance the chances of their field survival and also to determine which combinations of treatments are most effective for targeted species. If the artificial moss biocrusts can be grown efficiently in large quantities, we may have a powerful tool to combat dryland degradation syndromes, such as soil erosion and eco-hydrological dysfunctions.

\section{Conclusions}

This study assessed the physiological responses of artificial moss biocrusts to dehydration-rehydration process and heat stress using indoor experiments. The main conclusions are as follows. Artificial mosses can regulate the activities of protective enzymes and the contents of osmoregulatory substances to protect themselves during the dehydration-rehydration process. Thus, artificial moss biocrusts exhibit strong adaptability to the alternating wet and dry environments. Artificial moss biocrusts can also resist short-time heat stress, but they are unable to resist long-term heat stress. These results imply that non-lethal exposure of artificial moss biocrusts to drought and heat is a means to elevate their resistance to adverse conditions prior to field reintroduction.

\section{Acknowledgements}

This study was supported by the National Natural Science Foundation of China (41541008, 41671276), the Chinese Universities Scientific Fund (2014YQ006), the West Light Foundation of the Chinese Academy of Sciences (2014-91) and the Natural Science Foundation of Qinghai Province (2016-ZJ-943Q). The authors are grateful to YUAN Fang, LI Ruxue, YUAN Senpeng, ZHAO Yang, BAI Xueliang and LI Huiya who offered assistance. The authors thank anonymous reviewers and editors for their valuable comments.

\section{References}

Almeselmani M, Deshmukh P S, Sairam R K, et al. 2006. Protective role of antioxidant enzymes under high temperature stress. Plant Science, 171(3): 382-388.

Anderson J A. 2002. Catalase activity, hydrogen peroxide content and thermotolerance of pepper leaves. Scientia Horticulturae, 95(4): 277-284.

Antoninka A J, Bowker M A, Reed S C, et al. 2016. Production of greenhouse-grown biocrust mosses and associated cyanobacteria to rehabilitate dryland soil function. Restoration Ecology, 24(3): 324-335.

Ashraf M, Harris P J C. 2005. Abiotic Stresses: Plant Resistance Through Breeding and Molecular Approaches. New York: Howarth Press Inc., 370.

Bu C F, Wu S F, Yang Y S, et al. 2014. Identification of factors influencing the restoration of cyanobacteria-dominated biological soil crusts. PLoS ONE, 9(3): e90049, doi: 10.1371/journal.pone.0090049.

Bu C F, Zhang K K, Zhang C Y, et al. 2015. Key factors influencing rapid development of potentially dune-stabilizing moss-dominated crusts. PLoS ONE, 10(7): e0134447, doi: 10.1371/journal.pone.0134447.

Cao Y L, Zeng C H, Liu X B, et al. 2014. Physiological and biochemical response and drought resistance evaluation of four wild bryophytes. Journal of Northwest Forestry University, 29(4): 33-39. (in Chinese)

Chen W J. 2012. Study on rapid propagation system and physiological responses of stress of Haplocladium microphyllum. MSc Thesis. Hangzhou: Zhejiang A\&F University. (in Chinese)

Chen W J, Zhang N, Hang L L, et al. 2013. Influence of shading during the processes of drought stress and re-watering on the 
physiological and biochemical characteristics of Haplocladium microphyllum. Chinese Journal of Applied Ecology, 24(1): 57-62. (in Chinese)

Chen Y Q. 2009. Experimental research on artificial culture of mosses crusts in hilly Loess Plateau region. MSc Thesis. Yangling: Northwest A\&F University. (in Chinese)

Chiquoine L P, Abella S R, Bowker M A. 2016. Rapidly restoring biological soil crusts and ecosystem functions in a severely disturbed desert ecosystem. Ecological Applications, 26(4): 1260-1272.

Delgado-Baquerizo M, Maestre F T, Eldridge D J, et al. 2016. Biocrust-forming mosses mitigate the negative impacts of increasing aridity on ecosystem multifunctionality in drylands. New Phytologist, 209(4): 1540-1552.

Dhindsa R S, Matowe W. 1981. Drought tolerance in two mosses: correlated with enzymatic defence against lipid peroxidation. Journal of Experimental Botany, 32(1): 79-91.

Dionisio-Sese M L, Tobita S. 1998. Antioxidant responses of rice seedlings to salinity stress. Plant Science, 135(1): 1-9.

Doherty K D, Antoninka A J, Bowker M A, et al. 2015. A novel approach to cultivate biocrusts for restoration and experimentation. Ecological Restoration, 33(1): 13-16.

Feder M E, Hofmann G E. 1999. Heat-shock proteins, molecular chaperones, and the stress response: evolutionary and ecological physiology. Annual Review of Physiology, 61(1): 243-282.

Gao G L, Ding G D, Zhao Y Y, et al. 2014. Effects of biological soil crusts on soil particle size characteristics in the Mu Us Sandland. Transactions of the Chinese Society for Agricultural Machinery, 45(1): 115-120. (in Chinese)

Gulen H, Eris A. 2003. Some physiological changes in strawberry (Fragaria X ananassa 'Camarosa') plants under heat stress. The Journal of Horticultural Science and Biotechnology, 78(6): 894-898.

Guo C H, Sha W, Li X K. 2014. Effect of drought stress on physiological characteristics of three moss species. Northern Horticulture, (9): 78-82. (in Chinese)

He H R, Li Z D, Zhou E W, et al. 2008. Physiological responses to chilling of six warm-season turfgrasses. Acta Agrestia Sinica, 16(2): 150-153. (in Chinese)

Howarth C J. 2005. Genetic improvements of tolerance to high temperature. In: Ashraf M, Harris P J C. Abiotic Stresses: Plant Resistance Through Breeding and Molecular Approaches. New York: Howarth Press Inc., 277-300.

Iba K. 2002. Acclimative response to temperature stress in higher plants: approaches of gene engineering for temperature tolerance. Annual Review of Plant Biology, 53(1): 225-245.

Imlay J A. 2003. Pathways of oxidative damage. Annual Review of Microbiology, 57(1): 395-418.

Kang J M, Yang Q C, Fan F C. 2005. Effects of drought stress on induced protein in the different drought resistance alfalfa leaf. Acta Agrestia Sinica, 13(3): 199-202. (in Chinese)

Kärkönen A, Kuchitsu K. 2015. Reactive oxygen species in cell wall metabolism and development in plants. Phytochemistry, 112: $22-32$.

Lange O L. 2003. Photosynthesis of soil-crust biota as dependent on environmental factors. In: Belnap J, Lange O L. Biological Soil Crusts: Structure, Function, and Management. Berlin Heidelberg: Springer-Verlag, 217-240.

Liu Z Q, Zhang S C. 1994. Physiology of Plant Resistance. Beijing: China Agriculture Press, 97-111. (in Chinese)

Mayaba N, Beckett R P. 2003. Increased activities of superoxide dismutase and catalase are not the mechanism of desiccation tolerance induced by hardening in the moss Atrichum androgynum. Journal of Bryology, 25(4): 281-286.

McClung C R, Davis S J. 2010. Ambient thermometers in plants: from physiological outputs towards mechanisms of thermal sensing. Current Biology, 20(24): R1086-R1092.

McLetchie D N, Stark L R. 2006. Sporophyte and gametophyte generations differ in their thermotolerance response in the moss Microbryum. Annals of Botany, 97(4): 505-511.

Novo-Uzal E, Fernández-Pérez F, Herrero J, et al. 2013. From Zinnia to Arabidopsis: approaching the involvement of peroxidases in lignification. Journal of Experimental Botany, 64(12): 3499-3518.

Oliver M J, Bewley J D. 2010. Desiccation-tolerance of plant tissues: a mechanistic overview. In: Janick J. Horticultural Reviews, Volume 18. Hoboken, NJ: John Wiley \& Sons, Inc., 171-213.

Ortuño M F, Alarcón J J, Nicolás E, et al. 2005. Sap flow and trunk diameter fluctuations of young lemon trees under water stress and rewatering. Environmental and Experimental Botany, 54(2): 155-162.

Peter G, Leder C V, Funk F A. 2016. Effects of biological soil crust and water availability on seedlings of three perennial patagonian species. Journal of Arid Environments, 125: 122-126.

Proctor M C F, Oliver M J, Wood A J, et al. 2007. Desiccation-tolerance in bryophytes: a review. The Bryologist, 110(4): 595-621.

Robinson S A, Wasley J, Popp M, et al. 2000. Desiccation tolerance of three moss species from continental Antarctica. Australian Journal of Plant Physiology, 27(5): 379-388. 
Scandalios J G. 1997. Oxidizing the Genes Oxidative Stress and the Molecular Biology of Antioxidant Defences. New York: Cold Spring Harbor Laboratory Press, 383-388.

Scebba F, Sebastiani L, Vitagliano C. 1999. Protective enzymes against activated oxygen species in wheat (Triticum aestivum L.) seedlings: responses to cold acclimation. Journal of Plant Physiology, 155(6): 762-768.

Seel W, Hendry G, Atherton N, et al. 1991. Radical formation and accumulation in vivo, in desiccation tolerant and intolerant mosses. Free Radical Research Communications, 15(3): 133-141.

Seel W E, Hendry G A F, Lee J A. 1992. Effects of desiccation on some activated oxygen processing enzymes and anti-oxidants in mosses. Journal of Experimental Botany, 43(8): 1031-1037.

Shackel K A, Foster K W, Hall A E. 1982. Genotypic differences in leaf osmotic potential among grain sorghum cultivars grown under irrigation and drought. Crop Science, 22(6): 1121-1125.

Shen L, Guo S L, Yang W, et al. 2011. Physiological responses of Hypnum fertile Sendtn. (Musci: Hypnaceae) to short-term extreme temperature stress. Bulletin of Botanical Research, 31(1): 40-48.

Shi L R, Liu Z H. 2010. Influences of drought stress on antioxidative activity and osmoregulation substance of Sonchus brachyotus DC. Acta Agrestia Sinica, 18(5): 673-677. (in Chinese)

Stark L R, McLetchie D N. 2006. Gender-specific heat-shock tolerance of hydrated leaves in the desert moss Syntrichia caninervis. Physiologia Plantarum, 126(2): 187-195.

Stark L R, McLetchie D N, Roberts S P. 2009. Gender differences and a new adult eukaryotic record for upper thermal tolerance in the desert moss Syntrichia caninervis. Journal of Thermal Biology, 34(3): 131-137.

Stark L R, Greenwood J L, Brinda J C, et al. 2013. The desert moss Pterygoneurum lamellatum (Pottiaceae) exhibits an inducible ecological strategy of desiccation tolerance: Effects of drying rate on shoot damage and regeneration. American Journal of Botany, 100(8): 1522-1531.

Toldi O, Tuba Z, Scott P. 2009. Vegetative desiccation tolerance: Is it a goldmine for bioengineering crops? Plant Science, 176(2): 187-199.

Weber B, Bowker M A, Zhang Y M, et al. 2016. Natural recovery of biological soil crusts after disturbance. In: Weber B, Büdel B, Belnap J. Biological Soil Crusts: An Organizing Principle in Drylands. Ecological Studies Series. Berlin: Springer-Verlag, 479-498.

West N E. 1990. Structure and function of microphytic soil crusts in wildland ecosystems of arid to semi-arid regions. Advances in Ecological Research, 20: 179-223.

Wu N, Zhang Y M, Downing A, et al. 2012. Membrane stability of the desert moss Syntrichia caninervis Mitt. during desiccation and rehydration. Journal of Bryology, 34(1): 1-8.

Xia Q, He B H, Liu Y M, et al. 2010. Effects of high temperature stress on the morphological and physiological characteristics in Scaevola albida cutting seedlings. Acta Ecologica Sinica, 30(19): 5217-5224. (in Chinese)

Xiao B, Wang Q H, Zhao Y G, et al. 2011. Artificial culture of biological soil crusts and its effects on overland flow and infiltration under simulated rainfall. Applied Soil Ecology, 48(1): 11-17.

Xu G F, Zhang Z Y. 2009. Effect of high-temperature stress on physiological and biochemical indices of four Lysimachia plants. Chinese Journal of Eco-Agriculture, 17(3): 565-569. (in Chinese)

Xu S J, Liu C J, Jiang P A, et al. 2009. The effects of drying following heat shock exposure of the desert moss Syntrichia caninervis. Science of the Total Environment, 407(7): 2411-2419.

Yang H Y, Liu Y M, Wang T P. 2015. Effects of biological soil crusts on soil enzyme activities in a desert area. Acta Pedologica Sinica, 52(3): 654-664. (in Chinese)

Yang Y S, Feng W, Yuan F, et al. 2015. Key influential factors of rapid cultivation of moss crusts on Loess Plateau. Journal of Soil and Water Conservation, 29(4): 289-294, 299. (in Chinese)

Zhang X Q, Luo Z Q, Tang J G, et al. 2004. Effect of high temperature and drought stress on free proline content and soluble sugar content of Taxiphyllum taxirameum. Guihaia, 24(6): 570-530. (in Chinese)

Zhang Y M, Wang H L, Wang X Q, et al. 2006. The microstructure of microbiotic crust and its influence on wind erosion for a sandy soil surface in the Gurbantunggut Desert of Northwestern China. Geoderma, 132(3-4): 441-449.

Zou J. 2015. Effects of light intensity and temperature on photosynthesis of Syntrichia caninervis. MSc Thesis. Urumqi: Xinjiang University. (in Chinese) 